\title{
CYBER COUNSELING ASSISTED WITH FACEBOOK TO REDUCE ONLINE GAME ADDICTION
}

\author{
Hardi Prasetiawan \\ Prodi Bimbingan Konseling Fakultas Keguruan dan Ilmu Pendidikan \\ Universitas Ahmad Dahlan \\ hardi.prasetiawan@bk.uad.ac.id
}

\begin{abstract}
Cyber counseling dibagi menjadi berbagai bentuk, salah satu bentuknya adalah penggunaan facebook. Guru bimbingan dan konseling di sekolah dapat mengimplementasikan model cyber counseling berbantuan facebook untuk mereduksi kecanduan game online pada siswa yang lebih cenderung suka berkomunikasi dengan hubungan teks, dan siswa yang merasa tidak nyaman melakukan pelayanan bimbingan konseling secara face to face. Permasalahan anak yang kecanduan Game Online di sekolah memerlukan sebuah upaya bantuan dengan layanan Konseling Kelompok berbantuan facebook agar mampu mengatasi dan mengentaskan permasalahanpermasalahan yang dialaminya, baik yang bersifat pribadi maupun sosial melalui cyber counseling. Adapun dampak positif dalam pemberian layanan cyber counseling berbantuan facebook tidak lepas dari peran serta konselor sebagai pemberi layanan dan peran aktif siswa dalam mencari informasi di media sosial yaitu facebook, sehingga sosialiasi secara terus menerus perlu dilaksanakan lebih lanjut.
\end{abstract}

Keywords: Cyber Counseling, Facebook, Online Game Addiction

\section{PENDAHULUAN}

Jejaring sosial (social network) meskipun bukan kelompok formal, istilah jejaring sosial dibentuk dari pilihan-pilihan yang dilakukan individu untuk menjadi anggota berbagai kelompok (Gibson \& Mitchell, 2011:278). Sedangkan sumber lain mendefinisikan facebook sebagai berikut "facebook is the world's most popular social networking site, with more than 800 million active user (facebook.com) who primarily employ the site social purpose such as maintaining a network of offline relationship" (Bryant \& Marmo, 2010. Tong \& Walther, 2011).

Dari berbagai macam jenis jejaring sosial tersebut ada lima situs dipilih dengan berdasarkan jumlah pengguna terbanyak dan kriteria lainnya seperti kepopulerannya di Indonesia, yaitu: (1) Facebook, diperkirakan saat ini jumlah penggunanya mencapai 200 juta orang di seluruh dunia dan akan terus berkembang.
(2) Friendster, pernah menjadi salah satu situs terpopuler di Indonesia, walaupun sekarang digeser oleh facebook. Penggunanya di seluruh dunia diperkirakan mencapai 90 juta. (3) hi5, situs hi5 termasuk populer di beberapa negara di Asia tapi kurang populer di negara barat seperti Amerika Serikat. Jumlah penggunanya saat ini diperkirakan mencapai 80 juta. (4) Multiply, walaupun di negara Amerika Serikat tidak populer namun di Indonesia khususnya situs ini banyak dikenal dan diisi untuk meningkatkan jaringan. Penggunanya diperkirakan sekitar 10 juta. (5) Myspace, merupakan situs jejaring sosial yang memiliki jumlah pengguna terbesar di dunia. Diperkirakan saat ini jumlahnya mencapai 253 juta.

Menurut data statistik yang dilansir Check Facebook.com (situs yang dibentuk pada 13 Oktober 2008, dan diaplikasikan mulai 30 September 2009) mengatakan 
bahwa pada Oktober 2009, Indonesia menduduki peringkat ke-3 (20.265.080) pengguna facebook dunia, setelah United States (111.765.900) dan United Kingdom (23.514.620). Pada 1 Desember 2010, Indonesia mengalami kenaikan dalam penggunaan facebook yakni peringkat ke-2 dunia setelah United States (152.180.740) dengan data statistik 36.174.940, mengalahkan United Kingdom (28.940.400), disusul Turkey ((26. 417.820), kemudian Philipines (22.651.600). Pada 1 Desember 2010 sampai dengan bulan Maret 2011, Indonesia berada di peringkat 2 di bawah United States (Amerika Serikat), namun saat ini Indonesia digeser oleh India sehingga mengalami penurunan dan menjadi keringkat ke-3 dunia, dengan data statistik menunjukkan Amerika Serikat (155.701.780), India (43.497.980), Indonesia (43.060.360) disusul oleh Brazil (37.907.400) dan Maxico (32.034.880). Data statistik terbaru pada tahun 2012 menunjukkan Peringkat Pengguna facebook Indonesia Tahun 2012 mengalami penurunan dibanding tahun 2011, yaitu Indonesia menduduki peringkat ke-5 dunia dengan jumlah pengguna facebook sebanyak 23.3M, dengan urutan: (1) Portuguese (2) Arabic (3) German (4) Spanish (5) Indonesia (6) China (7) French (8) English (9) Italian (10) Turkish.

Pada jurnal yang ditulis oleh Efendi M. \& Naqiyah N. (2013:1) memaparkan berbagai permasalahan yang muncul dalam konseling antara lain: siswa ada yang merasa tidak nyaman untuk melakukan layanan secara face to face, siswa berpandangan bahwa bimbingan dan konseling sekolah sebagai tempat siswasiswa yang bermasalah, keterbatasan waktu guru BK dalam memberikan layanan konseling, rendahnya minat siswa untuk mengikuti layanan bimbingan konseling di sekolah, keterbatasan ruangan media dan pemanfaatan media tambahan sebagai kelengkapan dalam memberikan layanan konseling. Dari permasalahan yang dipaparkan tersebut, menggambarkan pentingnya pengembangan media dengan tujuan meningkatkan pemahaman materi yang disampaikan dalam layanan konseling.

Pemaparan di atas merupakan halhal yang mendeskripsikan bagaimana layanan konseling yang konvensional dapat dilakukan dengan cyber counseling melalui facebook dan hampir semua peserta didik memiliki akun facebook. Selain pertimbangan tersebut, ada berbagai kelebihan facebook dibanding dengan jejaring sosial yang lain yaitu facebook memiliki koneksi langsung pada layanan chatting yang disebut facebook chat, dapat meng-upload gambar dan video serta file dalam berbagai bentuk doc, pdf, jpg dengan sangat mudah digunakan yang tidak dimiliki jejaring sosial yang lain. Facebook juga merupakan jejaring sosial yang lebih famous dibanding dengan jejaring sosial lainnya.

Perkembangan game online juga tidak lepas dari perkembangan teknologi jaringan komputer. Perkembangan game online merupakan cerminan dari pesatnya jaringan komputer yang dahulunya berskala kecil "small local network" sampai menjadi internet.

Nugrahanto (2008) menjelaskan bahwa Departemen Komunikasi dan Informasi (Depkominfo) mengatakan, setidaknya ada tiga puluh juta orang Indonesia yang memainkan game online atau dengan kata lain, satu dari delapan orang Indonesia adalah pemain game online, karena kurangnya kemampuan untuk mengendalikan antusiasme terhadap sesuatu yang dapat membangunkan minat, para remaja dinilai lebih rentan melakukan penyimpangan penggunaan internet, seperti melarikan diri dari kehidupan nyata ke dunia maya seringkali diasosiasikan dengan masalah serius dalam keseharian remaja. Kegemaran bermain game online dikalangan remaja menimbulkan berbagai 
pengaruh negatif dalam perkembangan remaja.

Pengaruh negatif pemanfaatan internet mengakibatkan hubungan dengan teman dan keluarga menjadi renggang karena waktu yang digunakan untuk kumpul bersama menjadi jauh berkurang, sehingga anak menjadi terisolir dari teman-teman dan keluarga. Anak akan sulit konsentrasi terhadap pelajaran di sekolah karena terus menerus memikirkan game online yang senang dimainkan.

Cyber counseling berbantuan facebook sebagai media yang digunakan untuk mereduksi kecanduan game online dideskripsikan pada hal yaitu: (1) terdapat manfaat positif yang bisa diambil dari kecanggihan teknologi yang berkembang, (2) urgensi peningkatan layanan bimbingan konseling bagi siswa (3) pendapat Handarini (Noviyanti at al., 2011:1) yang menyatakan: "Teknologi dan internet dapat diterapkan dalam layanan konseling, yaitu: 1) layanan appraisal, 2) layanan informasi, 3) layanan Konseling, 4) layanan konsultasi, 5) layanan perencanaan, penempatan dan tindak lanjut dan 6) layanan evaluasi." Layanan yang diberikan dapat berupa layanan individu maupun layanan kelompok.

Adapun manfaat positif yang bisa diambil dari kecanggihan teknologi yang berkembang dalam penerapan keilmuan bimbingan dan kenseling antara lain:

1. Untuk memudahkan proses praktek konseling tanpa terhambat oleh jarak dan waktu, meningkatkan kualitas praktek bimbingan dan konseling.

2. Mengurangi kesenjangan digital.

3. Memperluas kesempatan belajar baik bagi konselor maupun bagi peserta didik yang selanjutnya disebut sebagai konseli.

4. Memfasilitasi untuk pembentukan keterampilan dan memudahkan konselor untuk menyimpan data administratif milik konseli.
5. Sebagai wahana bagi siswa yang seringkali merasa tidak nyaman untuk melakukan pertemuan secara langsung bertatap muka dengan seseorang ahli, maupun siswa yang lebih cenderung suka mengekplorasi diri dengan menulis/teks dari pada berbicara langsung. Karena membaca dan menulis juga merupakan sebuah bentuk terapi (Mcleod, J., 2010:496).

Salah satu kemampuan yang perlu dimiliki dan diterapkan oleh konselor sekolah adalah kemampuan memberi layanan bimbingan dan konseling baik dalam setting individu maupun kelompok. Baik layanan secara konvensional maupun cyber counseling. Sejauh ini banyak asumsi yang beranggapan bahwa konseling hanya dapat dilakukan secara face to face. Dengan adanya wajah baru cyber counseling ini, tidak semua konseling harus dilakukan dengan cara tatap muka. Akan tetapi, dapat pula dilakukan secara online, dan kemudian hubungan yang terjalin disebut dengan hubungan teks. Hubungan teks adalah Interaksi online yang terjadi melalui pertukaran pesan teks, baik di chating atau email dalam komunikasi berbasis teks, memiliki lebih banyak pengaturan, ada hubungan penting antara apa yang dikatakan dan bagaimana mengatakan (Kraus, R. at al, 2010:21-22).

Bagi seorang konselor sangatlah penting untuk memahami cyber counseling karena seiring dengan perkembangan teknologi modern, penerapan teknologi non internet kemungkinan sudah merata tetapi teknologi yang berbasis internet diperkirakan hanya beberapa sekolah dan kebiasaan berada diperkotaan. Sehingga kemungkinan penerapan teknologi khususnya diperuntukkan bagi layanan bimbingan dan konseling masih kecil karena selain dari segi biaya, kompetensi konselor pun menjadi tolak ukur. Kebanyakan konselor kurang memiliki keterampilan dalam mengelola aplikasi- 
aplikasi teknologi komputer berbasis internet, kecuali jika konselor tersebut mau meluangkan waktunya untuk belajar atau mempunyai teman yang ahli dalam bidang teknologi sehingga kerjasama tersebut bisa mempermudahkan dan memperluas pengetahuan konselor. Walaupun kemungkinan penerapannya masih kecil karena kendala biaya dan kompetensi konselor dalam melakukan cyber counseling berbantuan facebook bukan berarti hal tersebut tidak mungkin dilakukan.

\section{PEMBAHASAN}

a. Cyber Counseling

1) Pengertian Cyber Counseling

Seiring dengan perkembangan teknologi, konseling tidak hanya dapat dilakukan secara face to face namun bisa juga dilakukan dengan format jarak jauh yang dibantu dengan teknologi yang selanjutnya dikenal dengan istilah $e$ counseling (Gibson, 2008).

Jhon Bloom (2004) memiliki pendapat, konseling online adalah praktik konseling profesional dan pengiriman informasi yang terjadi ketika klien dan konselor berada pada lokasi yang terpisah, sehingga keduanya dapat mengatur dan memanfaatkan sarana elektronik untuk berkomunikasi melalui internet. Hal tersebut berarti tidak menutup kemungkinan bahwa sekolah bisa menggabungkan penggunaan internet dan jasa terkait lainnya, itu tak terelakkan bahwa bentuk konseling ini akan disediakan.

\section{2) Macam-Macam Cyber Counseling}

Konseling jarak jauh yang dibantu teknologi dibagi menjadi beberapa jenis, yaitu telekonseling dan konseling internet. Jenis-jenis telekonseling yaitu (1) konseling individual berdasarkan telepon, (2) konseling pasangan berdasarkan telepon, (3) konseling kelompok berdasarkan telepon. Sedangkan jenis-jenis konseling internet yaitu: (1) konseling individu berdasarkan e-mail, (2) konseling individual berdasarkan chat, (3) konseling pasangan berdasarkan chat, (4) konseling kelompok berdasarkan chat, (5) konseling individual berdasarkan video, (6) konseling pasangan berdasarkan video, (7) konseling kelompok berdasarkan video (Glading, S. T., 2012:602).

\section{b. Facebook}

1) Pengertian Facebook

Facebook adalah dibangun atas dasar model berbagi informasi pribadi untuk membangun komunitas (Lyons, 2010:22). Facebook resminya merupakan bagian dari budaya (Brew, L., Cervantes J. M., dan Shepard D., 2013:93). Pada akhirnya, penggunaan social network service dan terutama facebook menjadi bagian integral dari budaya milenium (Hazlett, 2008; Salaway et al., 2008). Situs jaringan sosial seperti facebook telah menjadi tempat yang sangat populer untuk komunikasi relasional, terutama di antara temanteman (Lampe, Ellison, \& Steinfield, 2006; Ellison at al, 2007). Seperti didefinisikan oleh Boyd dan Ellison (2007) :

Social network Service adalah layanan berbasis web yang memungkinkan individu untuk (1) Membangun profil publik atau semi-publik dalam sistem berikat, (2) Mengartikulasikan daftar pengguna lain dengan siapa mereka berbagi koneksi, dan (3) Pandangan dan melintasi daftar koneksi dan mereka dibuat oleh orang lain dalam sistem. Facebook saat ini memerintah sebagai Social network Service dunia paling populer dan dunia yang kedua paling diperdagangkan situs Internet (Alexa.com, diunduh 19 Desember 2013).

Berdasarkan pemaparan beberapa pendapat ahli di atas, dapat disimpulkan bahwa yang dimaksud dengan cyber counseling berbantuan facebook adalah suatu proses pemberian bantuan psikologis kepada siswa (konseli) secara online 
melalui facebook agar siswa dapat memenuhi kebutuhan akan konseling yang mereka perlukan, memahami, menerima dan mengarahkan dan mengaktualisasikan serta mengembangkan potensi dirinya secara optimal, untuk kepentingan hidup dan perkembangannya sebagai dasar pengambilan keputusan yang tepat.

2) Fitur-Fitur Facebook
(a) Status updates
(b) Timeline
(c) Friends
(d) Like
(e) Message dan inbox
(f) Provacy dan security
(g) News feeds
(h) Notification
(i) Graph search
(j) Network, group, pages
(k) Activity Log
(l) App Centre
(m) Search
(n) Nearby Places
(o) Facebook Chat
(p) Interest

3) Keunggulan Facebook Sebagai Media Cyber Counseling

Salah satu yang menjadi landasan dalam penyelenggaraan bimbingan dan konseling di sekolah adalah landasan ilmu pengetahuan dan teknologi. Moh. Surya (2006) mengemukakan bahwa sejalan dengan perkembangan teknologi komputer, interaksi antara konselor dengan individu yang dilayaninya (klien) tidak hanya dilakukan melalui hubungan tatap muka tetapi dapat juga dilakukan melalui hubungan secara virtual (maya) melalui internet, dalam bentuk cyber counseling. Untuk melakukan kegiatan cyber counseling, idealnya sekolah atau konselor yang bersangkutan dapat menyediakan website tersendiri yang dipergunakan khusus untuk kepentingan Bimbingan dan Konseling bagi para siswanya.
Cyber counseling tidak akan menggantikan konseling konvensional yang dilakukan dengan tatap muka. Namun, itu tidak dimaksudkan untuk menggantikan konseling konvensional melainkan cara lain untuk peduli dan membantu (Hussin, H., Ahmad, I. \& Othman M. H., dalam Jurnal cyber counseling for addiction and drug related problems:173-192). Ainsworth, M. (2006) menemukan bahwa 90\% dari orang-orang yang mencari bantuan online mengatakan bahwa itu membantu mereka. Berkomunikasi dengan seorang konselor melalui facebook massanger ini mungkin aman seperti berbicara untuk satu orang. Konselor online bertanggung jawab untuk melindungi privasi dan kerahasiaan selama tidak ada yang lain orang yang dapat memperoleh akses ke e-mail account. Menurut Tuti Iryani Mohd Daud, at al. (2005) Amerika Serikat Departemen Pendidikan 2003 dilaporkan 59\% anakanak dan remaja menggunakan internet. Sedangkan pelajar SMA rata-rata 90\% memiliki akun facebook.

\section{c. Kecanduan Game Online \\ Menurut Van Rooij (2011 : 66) video} game addiction as an addiction-like behavioral problem which presents as: a loss of control, an increase in conflict, preoccupation with gaming, the utilization of games for purposes of coping/mood modification, and withdrawal symptoms if the gamer is forced to quit.

Dari pengertian kecanduan game online di atas dapat dijelaskan bahwa kecanduan video game sebagai kecanduan seperti masalah perilaku yang menyajikan sebagai: hilangnya kontrol, peningkatan konflik, keasyikan dengan game, pemanfaatan permainan untuk tujuan mengatasi suasana-hati modifikasi, dan gejala penarikan jika gamer dipaksa untuk berhenti

Menurut Griffiths dan Kuss (2012 : 3) seseorang dikatakan kecanduan apabila 
memenuhi minimal tiga dari enam kriteria, yaitu sebagai berikut :

1. Salience : menunjukan dominasi aktivitas bermain game dalam pikiran dan tingkah laku.

a. Cognitive salience: dominasi aktivitas bermain game pada level pikiran.

b. Behavioral salience: dominasi aktivitas bermain game pada level tingkah laku.

2. Euphoria: mendapatkan kesenangan dalam aktivitas bermain game.

3. Conflict: pertentangan yang muncul antara orang yang kecanduan dengan orang-orang yang ada di sekitarnya (external conflict) dan juga dengan dirinya sendiri (internal conflict) tentang tingkat dari tingkah laku yang berlebihan.

a. Interpersonal conflict (eksternal): konflik yang terjadi dengan orangorang yang ada di sekitarnya.

b. Intrapersonal conflict (internal): konflik yang terjadi dalam dirinya sendiri.

4. Tolerance : aktivitas tersebut mengalami peningkatan secara progresif selama rentang periode untuk mendapatkan efek kepuasan.

5. Withdrawal : menarik diri atau menghentikan aktivitas bermain game online. Dengan menghentikan aktivitas tersebut, gejala yang akan ditimbulkan adalah munculnya perasaan cemas, gelisah atau tidak menyenangkan pada saat tidak melakukan aktivitas bermain game online.

6. Relapse and Reinstatement: kecenderungan untuk melakukan pengulangan terhadap pola-pola awal tingkah laku addictive atau bahkan menjadi lebih parah walaupun setelah bertahun-tahun hilang dan dikontrol. Kecenderungan untuk mengulang bermain game online menunjukan ketidakmampuan untuk berhenti secara utuh dari aktivitas bermain game online.

Sehingga, kecanduan game online adalah suatu aktivitas atau substansi terhadap suatu jenis permainan komputer berupa game online yang dilakukan berulang-ulang dan dapat menimbulkan dampak negatif. Khusus remaja yang masih di bangku sekolah, perlu menjadi bahan perhatian akibat kecanduan game online. Sesuatu yang dilakukan secara berlebihan tidak akan pernah berujung dengan baik. Remaja yang sudah kecanduan game online perlu diatasi melalui peer counseling agar remaja dapat saling memperhatikan dan mengatur waktu belajar dan bermainnya dengan baik sehingga lebih efektif dan efisien. Peer counseling dapat membantu remaja saling memperhatikan dan bertukar pengalaman agar terorganisasi dengan baik sehingga dapat membentuk remaja yang disiplin dan lebih bertanggung jawab.

Kecanduan game online adalah ketergantungan atau kondisi terikat yang sangat kuat secara fisik dan psikologis terhadap permainan game online, dan jika hasrat untuk memainkan game online tidak terpenuhi maka akan menimbulkan perasaan terhukum atau perasaan tidak menyenangkan bagi remaja yang bersangkutan. Dengan ketergantungan terhadap game onliine, remaja yang bersangkutan akan memperoleh kesenangan, kenyamanan serta keasyikan tersendiri sehingga frekuensi dan durasi dalam bermain game onliine akan terus meningkat dari waktu ke waktu, bahkan akan membuat semuanya tidak terkontrol, yang salah satunya berdampak pada situasi antisosial.

Ciri-ciri seorang remaja yang sudah kecanduan game online umumnya antara lain : marah apabila dibatasi waktunya 
untuk menggunakan bermain game online, cenderung enggan berkomunikasi dengan orang lain, bersifat tertutup atau hanya mau berteman dengan orang tertentu saja dan tidak mau melakukan aktivitas lain selain bermain game online. Selain itu, ada beberapa komponen-komponen inti yang bisa mengidentifikasi remaja yang kecanduan game online adalah salience, conflict dan euphoria. Sebagai tambahannya adalah tolerance, withdrawal, relapse dan reinstatement, komponen-komponen ini merupakan komponen umum dalam sebuah kecanduan. Tolerance berkembang sebagai kebutuhan pada seseorang yang kecanduan untuk meningkatkan ketergantungannya pada tingkah laku bermain game online untuk mendapatkan pengalaman yang sama dibandingkan pada saat bagian awal kecanduan. Efek withdrawal merupakan reaksi tidak menyenangkan pada saat menghentikan aktivitas kecanduan mereka. Sementara relapse dan reinstatement merupakan pengembalian kepada keadaan semula dari kecanduan, walaupun setelah periode penahanan aktivitasnya.

\section{KESIMPULAN}

Secara umum tujuan cyber counseling berbantuan facebook ini adalah meningkatkan pelayanan bagi seluruh peserta didik. Secara khusus tujuan pengembangan model cyber counseling berbantuan facebook ini sebagai wadah individu yang cenderung memililiki keterbatasan jarak, waktu, dan seringkali merasa tidak nyaman untuk melakukan pertemuan secara langsung bertatap muka dengan seseorang ahli, ketidaknyamanan ini terjadi dikarenakan situasi pertemuan profesional tersebut bersifat klinis. Hal tersebut didukung dengan pendapat Shaw \& Shaw (2006) mengatakan bahwa cyber counseling sangat cocok bila diberikan pada klien yang “....(c) yang tidak ingin melakukan konseling face to face (d) lebih suka menulis dari pada berbicara" (Gladding S.T., 2012:28). Oleh karena itulah individu yang memiliki kecanduan game online biasanya sesuai, cocok dan dapat menerima serta memiliki ketertarikan untuk menggunakan bentuk layanan e-counseling (Walther J.P., at al :2009).

Landasan cyber counseling berbantuan facebook ini digunakan sebagai bentuk untuk mempermudah dan memperkuat pencapaian manfaat layanan bimbingan dan konseling sebagaimana telah dipaparkan di atas. Shaw \& Shaw (2006) mengatakan: "Penggunaan teknologi dalam konseling telah tumbuh sangat cepat. Apa yang semula hanya janji, kini telah menjadi kenyataan, dan teknologi telah memberikan dampak yang kuat pada hampir semua aspek kehidupan, termasuk pendidikan..." (Gladding S.T., 2012:28).

Adapun situs-situs penyedia konseling online secara khusus memanfaatkan berbagai media online lainnya yang bisa digunakan untuk penyelenggaraan konseling online seperti jejaring sosial misalnya facebook, twitter, myspace, email, dan beberapa program aplikasi untuk chatting (instant messanging) seperti skype, yahoo messanger, google talk, window live messanger, bahkan menggunakan telepon dan handphone serta media teleconference lainnya. Pelayanan konseling online ini dilakukan konselor dalam upaya membantu mengentaskan dan menangani permasalahan klien. Beberapa tahun ke depan kebutuhan akan pelayanan konseling secara online akan terus meningkat (Ifdil at al., 2013:130). Keberadaan cyber counseling berbantuan facebook ini tidak bermaksud untuk menggeser layanan bimbingan konseling konvensional, akan tetapi cyber counseling berfungsi untuk melengkapi layanan bimbingan konseling secara konvensional 
(face to face) dalam ranah teknologi dan informasi.

\section{DAFTAR PUSTAKA}

Ainsworth, M. 2006. ABS's of Internet Therapy. http://www. metanoia.org/imhs/alliance.htm (diunduh 5 februari 2014).

Alexa.com, Social Network service. Diunduh 19 Desember 2013.

Brew, L., Cervantes J. M., dan Shepard D. 2013. "Millenial Counselors And The Ethical Us Of Facebook". Jurnal The Professional Counselor (TPC) Volume 3, Issue 2, hal. 93104.

Dari:

http://tpcjournal.nbcc.org

(diunduh 13 Desember 2013)

Bryant, E. M. dan Marmo, J. 2012. "The Rules Of Facebook Friendship: A Two-Stage Examination Of Interaction Rule In Close, Casual, And Acquaintance Priendships". Journal of social and personal relationships 29(8) hal 1013-1035. Diunduh dari: Sagepub.c.uk/journalsPermission.n av Hal. 2

Effendi, M. \& Naqiyah N. 2013. "Pengembangan Media Blog dalam Layanan Informasi Bimbingan \& Konseling”. Journal Online Universitas Negeri Surabaya. Vol.1 No.1 Hal: 1-20. Diunduh dari: http://ejournal.unesa.ac.id/index.p hp/jurnal-bk-unesa/article/view/ 1951/baca-artikel (diunduh 25 februari 2014)

Gibson, R. L. 2011. Bimbingan dan Konseling. Yogyakarta. Pustaka Pelajar.

Gibson, R.L. \& Mitchell M.H. 2008. Introduction to counseling and Guidance. New York: Macmillan Publisher.
Gladding, S.T.,. 2012. Konseling: Profesi yang Menyeluruh (edisi ke enam). Jakarta. Indeks.

Griffiths, M. D. \& Kuss, D. J. (2012). Online gaming addiction in children and adolescents: A review of empirical research. Journal of Behavioral Addictions, 1(1), 3-22. doi:10.1556/JBA.1.2012.1.1

Hazlett, B. 2008. Social Networking Statistics \& Trends [Slidshare]. (Diunduh 5 februari 2014) dari: http://www.slideshare.net/

Hussin, H., Ahmad, I. \& Othman M. H. (Ed.), "Cyber Counseling For Addiction And Drug Related Problems". Jurnal Antidadah Malaysia hal. 173-192

Ifdil, Ardi, Z., \& Yendi, F.M. 2013. "Konsep Dasar Konseling Online, permaasalahan dan tantangan”. Proseding. SIK-Malindo-2013 hal 129-135.

Kraus, R., Stricker G., dan Speyer C., 2010. Online Counseling: A handbook for Mental Health professionals (second edition). Elsevier. United States of America.

Lampe, C., Ellison, N., dan Steinfield, C. 2007. "A familiar Face(book): Profile Elements As Signals In An Online Social Network". Proseding. Proceedings of the SIGCHI Conference on Human Factors in Computing Systems (pp.435-444). New York, NY: ACM Press

Lyons, D. 2010. "The High Price Of Facebook: You Pay For It With Your Privacy”. News week. 24 dan 31 Mei 2010, hal. 22-22.

McLeod, J. 2006. Pengantar Konseling: Teori dan Studi Kasus. Jakarta. Kencana, Prenada Media Group.

Noviyanti, R. Dewi, dkk. 2011. "Layanan Konseling Berbasis TI". Makalah. Mata Kuliah Teknologi Informasi dalam Bimbingan dan Konseling 
Jurusan Psikologi Pendidikan dan Bimbingan UPI, Bandung.

Nugrahanto, Pradipta. 2008. Tips Memeilih Game Untuk Anak. Bandung: Yrama Widya

Surya, M. 2004. Psikologi Pengajaran dan Pembelajaran. Yogyakarta. Pustaka Bani Quraisy.

Tong, S. T., dan Walther, J. B. Relational Maintemence and CMC. N K. Wraight \& L. M. Webb (ed.). 2011. Computer Mediated Communication In Personal Relationships. New York: Peter Lang Publising. Hal. 98-118

Tuti Iryani, Mohd Daud, Zasmani Shafiee, at.al. 2005. The Pattern Of Help Seeking Behaviour Using The Internet Among Adoloscent.

Van Rooij, A. J. (2011). Online Video Game Addiction. Exploring a new phenomenon [PhD Thesis]. Rotterdam, The Netherlands: Erasmus University Rotterdam. 